\title{
Impacto do distanciamento social na rotina de crianças e adolescentes com
}

\section{Transtorno do Espectro Autista}

Impact of social distancing in the routine of children and teenagers with Autism Spectrum Disorder Impacto del distanciamiento social en la rutina de niños y adolescentes con Trastorno del Espectro

Carlos Eduardo Ramos Ataide ORCID: https://orcid.org/0000-0003-3677-3665 Universidade do Estado do Pará, Brasil E-mail: c.eduardoataide@gmail.com

Nathália Thalita Corrêa Miranda ORCID: https://orcid.org/0000-0002-0839-963X Universidade do Estado do Pará, Brasil E-mail: nathtalita24@gmail.com

Nicole Giovanna da Silva Ribeiro ORCID: https://orcid.org/0000-0002-0802-9022 Universidade do Estado do Pará, Brasil E-mail: nicolegiovannas2@gmail.com Luciane Ferreira Farias ORCID: https://orcid.org/0000-0003-4557-1248 Universidade Federal do Pará, Brasil

E-mail: lucianeferreirafariass@gmail.com Bruna Tayná Brito Gama ORCID: https://orcid.org/0000-0002-9948-3406 Escola Superior da Amazônia, Brasil E-mail: tobrunagama@gmail.com

Karina Saunders Montenegro

ORCID: https://orcid.org/0000-0002-6733-8642 Universidade do Estado do Pará, Brasil E-mail: karinasmonte@yahoo.com.br

\begin{abstract}
Resumo
Em tempos de COVID-19, o distanciamento social é essencial para evitar a propagação do vírus e manter a população protegida, porém, isto acarreta grandes mudanças nas rotinas dos indivíduos de maneira geral. Entre estes, estão as crianças e adolescentes com Transtorno do Espectro Autista (TEA), que podem estar sujeitas a maiores impactos devido apresentarem resistência a mudanças devido os padrões de comportamentos restritos. Diante disso, busca-se analisar os impactos do distanciamento social na rotina diária de crianças e adolescentes com TEA. Trata-se de uma pesquisa transversal de abordagem quantitativa, realizada através do Formulário Google, criado pelos autores e composto por 37 perguntas, respondido pelos responsáveis de crianças e adolescentes com TEA. A maioria das crianças estavam na primeira infância com grau leve na classificação do Transtorno; observou-se aumento nos problemas de comportamento, surgimento de problemas alimentares; a maioria das crianças sentem falta da escola e estão realizando atividades alternativas; houve, também, aumento na dificuldade em aceitar atividades fora do ambiente escolar; os responsáveis tiveram maior participação no lazer. Constatou-se a repercussão negativa ocasionada pelo distanciamento social concomitante a descontinuidade do tratamento especializado das crianças e adolescentes com TEA; que desencadearam ou intensificaram os comportamentos disruptivos.
\end{abstract}

Palavras-chave: Transtorno do espectro autista; COVID-19; Terapia ocupacional.

\begin{abstract}
In times of COVID-19, social distance is essential to prevent the virus' spread and to keep the population protected, however, this causes major changes in routines of individuals in general. Among these are children and adolescents with Autistic Spectrum Disorder (ASD), who may be subject to greater impacts due to their resistance to changes due to restricted patterns of behavior. To analyze the impacts of social distance on the daily routine of children and adolescents with ASD. Cross-sectional research with a quantitative approach, carried out through the Google Form, which was composed of 37 questions, with the legal guardians of children and adolescents with ASD. The largest audience were children in early childhood with a mild degree in the disorder's classification; there was an increase in behavioral problems, emergence of compulsion or rejection of food; most children miss school and are doing alternative
\end{abstract}


activities; there was also an increase in the difficulty in accepting activities outside the school environment; those responsible for the children had a greater participation in leisure. The negative repercussion caused by the social detachment concomitant with the discontinuity of specialized treatment of children and adolescents with ASD was found; that triggered or intensified the disruptive behaviors.

Keywords: Autism spectrum disorder; COVID-19; Occupational therapy.

\section{Resumen}

En tiempos de COVID-19, el distanciamiento social es fundamental para prevenir la propagación del virus y mantener a la población protegida, sin embargo, esto conlleva grandes modificaciones en las rutinas de los individuos en general. Entre ellos, están los niños y adolescentes con Trastorno del Espectro Autista (TEA), que pueden ser objeto de mayores impactos por su resistencia al cambio debido a patrones de comportamiento restringidos. Por lo tanto, este estudio tiene como objetivo analizar los impactos del distanciamiento social en la rutina diaria de los niños y adolescentes con TEA. Se trata de una investigación transversal con enfoque cuantitativo, realizada a través del Formulario Google, creado por los autores y compuesto por 37 preguntas, respondidas por los tutores de niños y adolescentes con TEA. La mayoría de los niños se encontraban en la primera infancia con un grado leve en la clasificación del trastorno; hubo un aumento de los problemas de comportamiento, aparición de problemas de alimentación; la mayoría de los niños querían ir a la escuela y están realizando actividades alternativas; también hubo un aumento de la dificultad para aceptar actividades fuera del entorno escolar; los cuidadores tuvieron una mayor participación en el tiempo libre. Se verificó la repercusión negativa causada por el distanciamiento social concomitante a la discontinuidad del tratamiento especializado de los niños y adolescentes con TEA; que desencadenó o intensificó las conductas disruptivas.

Palabras clave: Trastorno del espectro autista; COVID-19; Terapia ocupacional.

\section{Introdução}

No final do ano de 2019, a China registrou os primeiros casos da Coronavirus Disease 2019 (COVID-19), onde o agente patológico da mesma é o novo coronavírus Severe Acute Respiratory Syndrome Coronavirus 2 (SARS-CoV-2). Esta doença apresenta quadros clínicos que variam de assintomáticos às pneumonias severas, onde as populações idosas e com comorbidades são mais suscetíveis aos casos graves e fatais. Diante deste cenário, a Organização Mundial da Saúde (OMS) anunciou, em 11 de março de 2020, a pandemia da COVID-19 (Macêdo, Adriana, Auzeni \& França, 2020; OPAS, 2020).

Os sinais e sintomas observados nesta patologia são: tosse, febre, coriza, dor de garganta e dificuldade respiratória. Também pode ser identificado dor de cabeça, ausência de paladar e olfato, conjuntivite, erupção cutânea na pele ou descoloração dos dedos das mãos ou dos pés (Brasil, 2020).

Segundo a Organização Pan-Americana da Saúde (2020) a transmissão ocorre a partir de um sujeito infectado para outro saudável através de aperto de mãos, espirro, gotículas de saliva, secreção, tosse e objetos ou superfícies contaminadas. Diante disso, recomendou-se a adoção de medidas preventivas, como: higienizar as mãos frequentemente com água e sabão ou álcool em gel, cobrir a boca e o nariz com o antebraço ao tossir ou espirrar, fechamento de espaços de circulação de pessoas e de serviços não essenciais, distanciamento social, quarentena e isolamento social (Silva, Silva, Rabelo \& Vinhas, 2020).

A OMS priorizou e recomendou o distanciamento social por apresentar-se como forma de contenção da disseminação do novo coronavírus e para prevenir a sobrecarga no serviço de saúde mundial.

Corrêa, Nascimento e Omura (2020) ressaltaram que estas medidas implicaram em um afastamento temporário de diversas atividades, o que acarretou em mudanças expressivas no cotidiano de pessoas ao redor do mundo. Logo, salienta-se a importância de atentar-se ao impacto disso nas rotinas, bem como as implicações na saúde mental, física e no bem-estar (Silva, Mariotti \& Bridi, 2020).

Com isso, destacam-se as crianças e adolescentes com Transtorno do Espectro Autista (TEA), que apresentam dificuldades como aceitar mudanças na rotina e interesses restritos. A interrupção repentina na rotina pode acarretar em crises de comportamentos repetitivos, estereotipados, auto e heterolesivos. Também podem apresentar confusão, aflição e dificuldade em seguir e generalizar comandos que antes estavam acostumados, isso causa-lhes insegurança e ansiedade, devido à incerteza e imprevisibilidade (APA, 2014; Dartora, Mandieta \& Franchin, 2014). 
Neste contexto de pandemia, crianças e adolescentes com TEA vivenciaram uma quebra em sua rotina através da brusca interrupção de seus tratamentos terapêuticos e educacionais. O distanciamento social impossibilitou o restabelecimento da rotina a curto prazo, o que ocasionou em diminuição no apoio que esses e suas famílias recebiam de profissionais especialistas (Souza, 2020; Narzisi, 2020).

Diante do exposto, objetivou-se analisar os impactos do distanciamento social na rotina de crianças e adolescentes com TEA. A pesquisa mostra-se necessária, pois os resultados possibilitarão estudos e intervenções na perspectiva de amenizar os impactos e contribuir para maior conhecimento dos responsáveis e dos profissionais que atuam nesta área e da população em geral.

\section{Metodologia}

Estudo transversal de abordagem quantitativa, o qual se constitui como um método que visa objetividade e representação da realidade do seu objeto de estudo através da quantificação de dados e amostras coletadas, assim faz-se possível mensurar e quantificar as respostas obtidas durante a coleta, que podem confirmar ou contestar as hipóteses levantadas (Gerhardt e Silveira, 2009). Dessa forma, esse estudo foi realizado a partir de um formulário distribuído em todo país, com início em abril e finalizado em junho de 2020.

A seleção dos participantes ocorreu por meio do contato com redes sociais de associações e grupos de famílias de pessoas com TEA. Participaram deste estudo 65 responsáveis de crianças e/ou adolescentes diagnosticados com TEA, na faixa etária de 2 a 19 anos de idade, que residiam no Brasil, e que vivenciaram o distanciamento social em virtude da pandemia do novo Coronavírus, que possuíam acesso à internet para poder responder ao questionário. Não puderam participar da pesquisa aqueles que não assinaram do Termo de Consentimento Livre e Esclarecido (TCLE).

Utilizou-se como instrumento de coleta de dados um formulário, desenvolvido pelos pesquisadores, com 37 perguntas divididas em 6 categorias: I. Dados sociodemográficos dos responsáveis e da criança ou adolescente; II. Comportamentos; III. Contexto Escolar; IV. Alimentação; V. Lazer e VI. Terapias. Este formulário foi desenvolvido no google docs.

Os dados obtidos foram organizados na planilha do Microsoft Office Excel, gerada pelo próprio formulário google docs. Em seguida, realizou-se as análises descritivas dos dados, através de porcentagem, média e frequência. O programa utilizado nesta etapa foi o SPSS v.22.0.

Este estudo foi encaminhado ao Comitê de Ética em Pesquisa do Centro de Saúde Escola do Marco da Universidade Estado do Pará - CESEM/UEPA, aprovado sobre o parecer: 4.242.665.

\section{Resultados e Discussão}

O perfil dos participantes da pesquisa apresentou diferença quanto ao gênero, $92,3 \%$ do sexo feminino, o que representa 60 respostas. Dentro desse grupo encontravam-se majoritariamente as mães com 81,54\% (n=53). Nos estudos de Faro et al. (2020) sobre mães de crianças com TEA, foi observada uma sobrecarga de estresse e de múltiplas atividades em sua rotina, essas mulheres também tendiam a reduzir a carga horária de trabalho ou a abandoná-lo para cuidar de forma integral de seu filho (Soares, Da Silva, Santos \& Gama, 2020).

Quanto ao estado civil, os sujeitos declarados casados representaram 52,30\% $(n=34), 30,78 \%(n=20)$ dos participantes se declararam solteiros e 15,39\% ( $\mathrm{n}=10$ ) divorciados. A maioria dos responsáveis estavam na faixa etária de 36 a 40 anos, cerca de 26,15\% ( $n=17$ ), seguida por participantes de 31 a 35 anos com 24,61\% ( $n=16)$.

A maioria das crianças estavam na primeira infância, entre 1 a 5 anos de idade, um total de 49,21\% (n=32), seguido da faixa etária de 6 a 10 anos 36,95\% (n=24) e 13,85\% (n=9) estavam entre 11 a 15 anos. Quanto ao grau de classificação do 
Transtorno, 43,10\% ( $\mathrm{n}=28)$ das crianças ou adolescentes apresentam o grau leve e 41,50\% (n=27) moderado. Ressalta-se que $12,30 \%(n=8)$ dos responsáveis não souberam responder acerca do grau, e apenas 3,10\% (n=2) das crianças eram classificadas no grau severo. Segundo os responsáveis, 76,92\% $(\mathrm{n}=50)$ das crianças e adolescentes não apresentavam comorbidades, transtornos ou condições associadas ao TEA.

A pesquisa alcançou as cinco regiões brasileiras, onde abrangeu significativamente a região norte com 44,61\% ( $\mathrm{n}=29)$, seguido do nordeste representado por 30,76\% $(n=20)$, região sul 12,30\% ( $n=8)$, depois centro-oeste com 7,79\% $(n=5)$ e por fim, sudeste indicado com $4,61 \%(n=3)$ das respostas.

Após a análise do perfil dos participantes da pesquisa, iniciou-se a análise das outras 5 categorias. Os resultados comparativos entre o antes e o depois do início do distanciamento, que tratavam dos comportamentos, alimentação e contexto escolar dizem respeito à frequência semanal da emissão ou não de cada situação questionada, enquanto que na categoria lazer a frequência é dada a partir de horas diárias.

Na Tabela 1, é possível comparar a frequência semanal de comportamentos, antes e durante o isolamento social.

Tabela 1. Frequência semanal de comportamentos antes e durante o isolamento social.

\begin{tabular}{|c|c|c|}
\hline COMPORTAMENTOS & ANTES & DEPOIS \\
\hline \multicolumn{3}{|l|}{ Heterolesivos } \\
\hline Não ocorre & $72 \%$ & $52 \%$ \\
\hline 1 a 2 & $23 \%$ & $23 \%$ \\
\hline 3 a 4 & $5 \%$ & $23 \%$ \\
\hline 5 a 6 & $0 \%$ & $0 \%$ \\
\hline 7 a 8 & $0 \%$ & $2 \%$ \\
\hline 9 a 10 & $0 \%$ & $0 \%$ \\
\hline mais & $0 \%$ & $0 \%$ \\
\hline \multicolumn{3}{|l|}{ Autolesivo } \\
\hline Não ocorre & $78 \%$ & $66 \%$ \\
\hline 1 a 2 & $12 \%$ & $21 \%$ \\
\hline 3 a 4 & $8 \%$ & $11 \%$ \\
\hline 5 a 6 & $2 \%$ & $2 \%$ \\
\hline 7 a 8 & $0 \%$ & $0 \%$ \\
\hline 9 a 10 & $0 \%$ & $0 \%$ \\
\hline mais & $0 \%$ & $0 \%$ \\
\hline \multicolumn{3}{|l|}{ Birras } \\
\hline Não ocorre & $15 \%$ & $5 \%$ \\
\hline 1 a 2 & $52 \%$ & $30 \%$ \\
\hline 3 a 4 & $26 \%$ & $49 \%$ \\
\hline 5 a 6 & $5 \%$ & $6 \%$ \\
\hline 7 a 8 & $0 \%$ & $2 \%$ \\
\hline 9 a 10 & $0 \%$ & $3 \%$ \\
\hline mais & $2 \%$ & $5 \%$ \\
\hline
\end{tabular}




\begin{tabular}{ccc}
\hline Ecolalia & & \\
\hline Não ocorre & $26 \%$ & $23 \%$ \\
1 a 2 & $32 \%$ & $21 \%$ \\
3 a 4 & $29 \%$ & $35 \%$ \\
5 a 6 & $2 \%$ & $8 \%$ \\
7 a 8 & $2 \%$ & $2 \%$ \\
9 a 10 & $6 \%$ & $5 \%$ \\
mais & $3 \%$ & $6 \%$ \\
\hline Flapping & & \\
\hline Não ocorre & $40 \%$ & $32 \%$ \\
1 a 2 & $31 \%$ & $23 \%$ \\
3 a 4 & $16 \%$ & $23 \%$ \\
5 a 6 & $5 \%$ & $12 \%$ \\
7 a 8 & $0 \%$ & $0 \%$ \\
9 a 10 & $6 \%$ & $5 \%$ \\
mais & $2 \%$ & $5 \%$ \\
\hline
\end{tabular}

Fonte: Autores (2021).

$\mathrm{Na}$ Tabela acima, são apresentadas as ocorrências antes e durante a pandemia em seu momento mais crítico no ano de 2020. Faz-se possível observar a frequência semanal do quanto esses comportamentos autolesivos, heterolesivos, birras, ecolalias e de flapping ocorriam.

Verifica-se que antes da pandemia a maioria das crianças e adolescentes não apresentavam comportamentos heterolesivos e que no contexto de isolamento estes comportamentos se tornaram mais frequentes.

Devido ao fato da COVID-19 ter afetado diversos aspectos na vida dos indivíduos em geral, mudanças de hábitos tiveram que ser feitas. O ficar em casa devido a necessidade de distanciamento social, a fim de evitar a propagação do vírus, levou a um impacto significativo nas rotinas diárias de crianças e famílias, tendo de adaptar o horário da alimentação, a necessidade de lidar com um maior movimento na casa, entre outras questões. Este fato implica diretamente no grupo de crianças com TEA, uma vez que possuem entre suas principais características a rigidez em relação a mudanças e uma adesão em excesso a rotinas, que faz esse momento pandêmico um grande desafio para muitas (APA, 2014; Kalvin et al., 2021).

Em relação aos comportamentos autolesivos, é apontado que houveram mudanças significativas, com diminuição da "não ocorrência" e aumento na frequência de comportamentos autolesivos de 1 a 2 vezes e 3 a 4 vezes por semana. Os estudos de Colizzi et al., (2020) também identificaram que houve um aumento dos problemas de comportamento em indivíduos com TEA durante o isolamento social.

Destaca-se que comportamento heterolesivo consiste em uma agressão física a qual é direcionada ao outro, geralmente relacionada com o objetivo de conseguir algo e fugir daquilo que é considerado pela criança como desagradável no momento (Borba \& Barros, 2018). Comportamentos autolesivos são agressões direcionadas a si de forma compulsiva, ou seja, sem planejamento e, na maioria das vezes, com ritmo (Torras, 2019).

Em relação a birra, trata-se de uma palavra utilizada para descrever comportamentos inadequados (chorar, gritar, quebrar, jogar e empurrar objetos, entre outros) que a criança faz uso como uma forma de comunicar o que quer ou não (Borba \& Barros, 2018). A ecolalia costuma ser definida como a repetição da fala de outras pessoas, de acordo com Sterponi e Kirby 
(2016), sendo associada a um repertório empobrecido de ações comunicativas. Por fim, quanto ao flapping, este é uma estereotipia motora - caracterizada por movimentos repetitivos e rítmicos -, a qual consiste em balançar os braços ou mãos como se fossem asas, conforme o estudo de Barros e Fonte (2016).

Pessoas com TEA e com comportamentos inadequados preexistentes apresentaram maior frequência de birras em comparação aos que não possuem estas especificidades. Logo, uma em cada três crianças demonstraram problemas de comportamento mais intensos resultantes das implicações da COVID-19 nas rotinas (Colizzi et al., 2020). Nesta pesquisa, o comportamento de birra houve um aumento significativo entre antes e depois, especialmente na opção de 3 a 4 vezes por semana, de $26 \%(n=17)$ por semana para $49 \%(n=32)$.

Quanto as ecolalias, houve diminuição da "não ocorrência", e um aumento importante nas frequências de 3 a 4, e 4 a 6 vezes por semana. Quanto ao flapping, estereotipia mais comum no TEA, os resultados apontam que as crianças e adolescentes do estudo apresentaram um aumento expressivo. Destaca-se também que antes da pandemia 40\% (n=26) das crianças não apresentavam este comportamento.

Ao comparar proporcionalmente a ocorrência dos 3 comportamentos disruptivos (heterolesivo, autolesivo e birras) o maior aumento, em média, foi na birra com 30,76\%, seguido da heteroagressividade $20 \%$ e autoagressão $10,76 \%$.

Quanto as estereotipias apresentadas no estudo o flapping apresentou maior crescimento com 16,92\% e as ecolalias apenas com $15,38 \%$.

Quanto as questões alimentares, identificaram-se a ocorrência de comportamentos de compulsão e de recusa alimentar como repercussões do distanciamento social. O gráfico 1 mostra se houveram aumentos na frequência de recusa de alimentos durante o momento crítico da pandemia. No que concerne à recusa de alimentos, 42\% (n=27) dos responsáveis relataram que não ocorria antes do distanciamento social e durante o mesmo. Além disso, a recusa de alimentos de 1 a 2 vezes por semana reduziu durante o distanciamento, entretanto, a recusa de 3 a 4 vezes aumentou expressivamente, como observa-se no Gráfico 1 abaixo:

Gráfico 1. Recusa de alimentos.

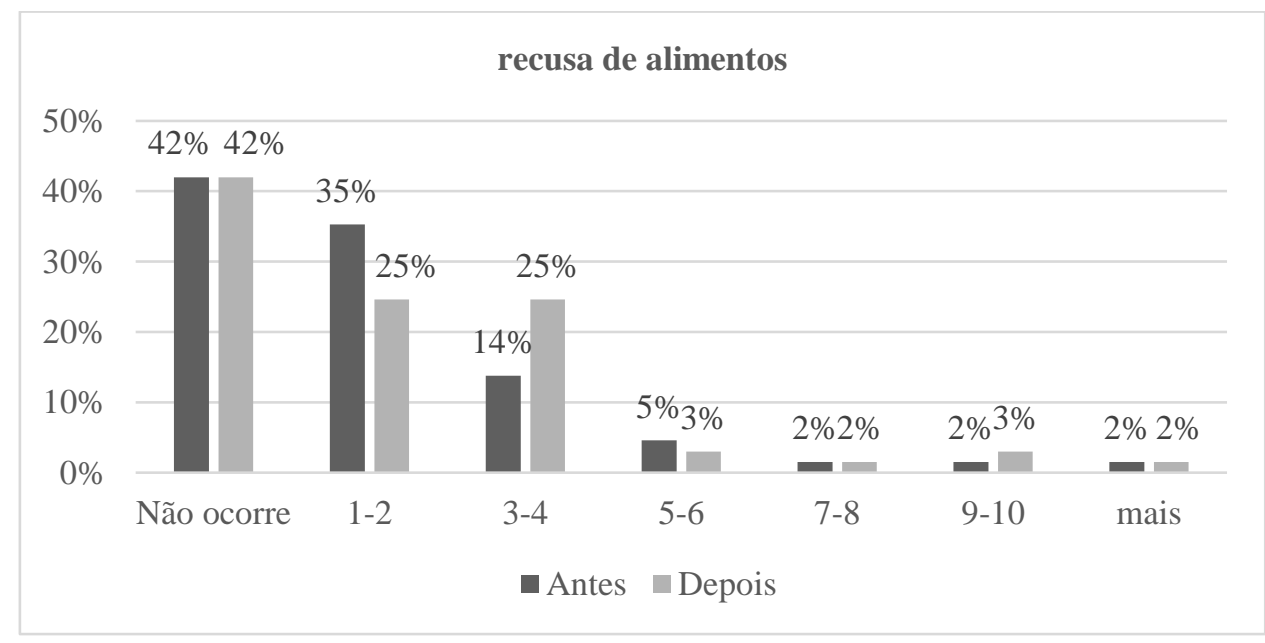

Fonte: Autores (2021).

Estes dados corroboram com a pesquisa de Bellomo et al. (2020) Outros estudos também observaram que o isolamento social repercutiu significativamente na alimentação das crianças e adolescentes com TEA e uma das causas é a dificuldade do acesso aos seus alimentos de preferência (Monteiro, Assumpção, Martins \& Valéria, 2020).

Segundo Rodgers e colaboradores et al. (2020), a pandemia do COVID-19 e as restrições das atividades provocaram a 
desestruturação de rotinas, o que provocou potenciais riscos para o desenvolvimento ou exacerbação de disfunções alimentares.

Em relação à introdução de alimentos com texturas anteriormente aceitas pelas crianças e adolescentes, $72 \%(n=47)$ dos responsáveis relataram que não modificou e $23 \%(\mathrm{n}=15)$ afirmaram alterações no decorrer da quarentena. A respeito das alterações na preferência alimentar, 69\% ( $\mathrm{n}=45)$ não observaram e $28 \%(\mathrm{n}=18)$ identificaram. Em ambos os questionamentos, $3 \%(\mathrm{n}=2)$ não souberam responder respectivamente.

Ressalta-se que as alterações na alimentação são frequentes em crianças com TEA. Esses podem apresentar alterações alimentares devido às disfunções no processamento sensorial, problemas de motricidade oral, como dificuldade na sucção e mastigação ou devido a ocorrência de interesses restritos e a resistência às mudanças (Zobel-lachiusa, Andrianopoulos, Mailloux \& Cermak, 2015; Lázaro \& Pondé, 2017).

Quanto aos dados coletados acerca do desenvolvimento de atividades escolares, questionou-se se a criança ou o adolescente demonstrou sentir falta da escola. Quanto a isso, 66,15\% $(n=43)$ responderam que as crianças/adolescentes com TEA sentiram "sim" a falta do ambiente escolar presencial, segundo Fernandes, Monteiro e Marques (2020) isso deve-se ao fato que as mudanças que ocorrem no cotidiano possuem grande potencial de produzir sofrimento, em razão dos comportamentos inflexíveis e disruptivos. Por outro lado 26,15\% (n=17) responderam que "não" sentiam falta e 4,64\% (n=3) não souberam identificar se o sujeito com TEA sentiu falta da escola, isso pode ter ocorrido devido à dificuldade em expressar os próprios sentimentos de uma forma que os outros possam compreendê-los. Por outro lado, 3,06\% $(n=2)$ não estavam inseridas no contexto escolar presencial, logo, o questionamento do tópico não se aplicava.

Quanto a realização de atividades para suprir a ausência de aulas presenciais, identificou-se que 73,83\% (n=48) dos responsáveis responderam que as crianças realizavam atividades em casa, $21,53 \%(\mathrm{n}=14)$ disseram que não estava ocorrendo e 4,64\% ( $\mathrm{n}=3$ ) responderam que este tópico não se aplicava. De acordo com Brito, Almeida, Crenzel, Alves, Lima, Abranches (2020) a manutenção de atividades durante o isolamento social é importante para reduzir reações comportamentais drásticas diante da dificuldade com mudanças de rotina, o autor aconselha acompanhar as propostas da escola.

Também, buscou-se saber quais atividades escolares estavam acontecendo, foram citadas diversas atividades, pois não havia limitação no número das respostas.

As atividades impressas foram citadas em 52,3\% ( $\mathrm{n}=34), 32,3 \%(\mathrm{n}=21)$ assistiam vídeo aula, 2,3\% ( $\mathrm{n}=2)$ disseram que o público estava de férias, $6,15 \%(n=4)$ estavam inseridos em brincadeiras educativas, em $21,5 \%(n=14)$ dos casos, o questionamento não se aplicava.

A pesquisa de Araripe et al. (2019) enfatiza a necessidade em repensar os objetivos do Plano de Ensino Individualizado para proporcionar aos estudantes com TEA as adaptações necessárias.

Destaca-se as vídeo aulas, que surgiram como um novo recurso na educação infantil que permite o acompanhamento dos alunos na modalidade online. E representou a segunda maior prevalência nesta pesquisa. Esta modalidade de ensino permite o encurtamento da distância entre professor-aluno-família. Entretanto, deve-se levar em consideração que no caso de alunos com TEA, o ambiente escolar é importante e não pode ser totalmente substituído pelo atendimento online, pois ele representa um contexto adequado para a interação social e troca entre pares (Da Silva, Silveira \& Prsybyciem, 2020).

Cusinato et al. (2020) traz que o acompanhamento do encontro virtual com o professor no mesmo horário em que criança frequentava a escola, também, vestir o uniforme escolar e pausa para recreio, são bons mecanismos para os alunos com TEA, uma vez que garante uma rotina mais próxima da mantida na escola.

As atividades impressas dos alunos com TEA da pesquisa e as brincadeiras educativas são frutos da lei brasileira de inclusão 13.146/15 que, em seu capítulo IV, o artigo 28 , inciso $7^{\circ}$, garante ao aluno do sistema público de ensino da educação especial condições pedagógicas, mediações e recursos à aprendizagem. Assim, a variabilidade e modalidades distintas garantem ao aluno inclusão e aprendizagem dos conhecimentos escolares. 
Faz-se fundamental a implementação de uma rotina de atividades planejadas e orientadas pelo profissional do apoio educacional especializado que acompanha o desenvolvimento e reconhece as possibilidades de adaptação com enfoque nas condições atuais de confinamento (Barbosa, Figueiredo, Viegas \& Batista, 2020).

Além disso, os responsáveis responderam sobre as dificuldades das crianças e adolescentes em aceitar as atividades educativas/pedagógicas fora do ambiente escolar. O Gráfico 2 apresenta se houveram tais dificuldades citadas, com isso, identificou-se que a maioria dos participantes não apresentava dificuldades antes da pandemia. Após o início da pandemia, parte do público apresentou dificuldades com frequência de 3 a 4 vezes por semana durante o distanciamento social.

Gráfico 2. Dificuldades em aceitar atividades escolares.

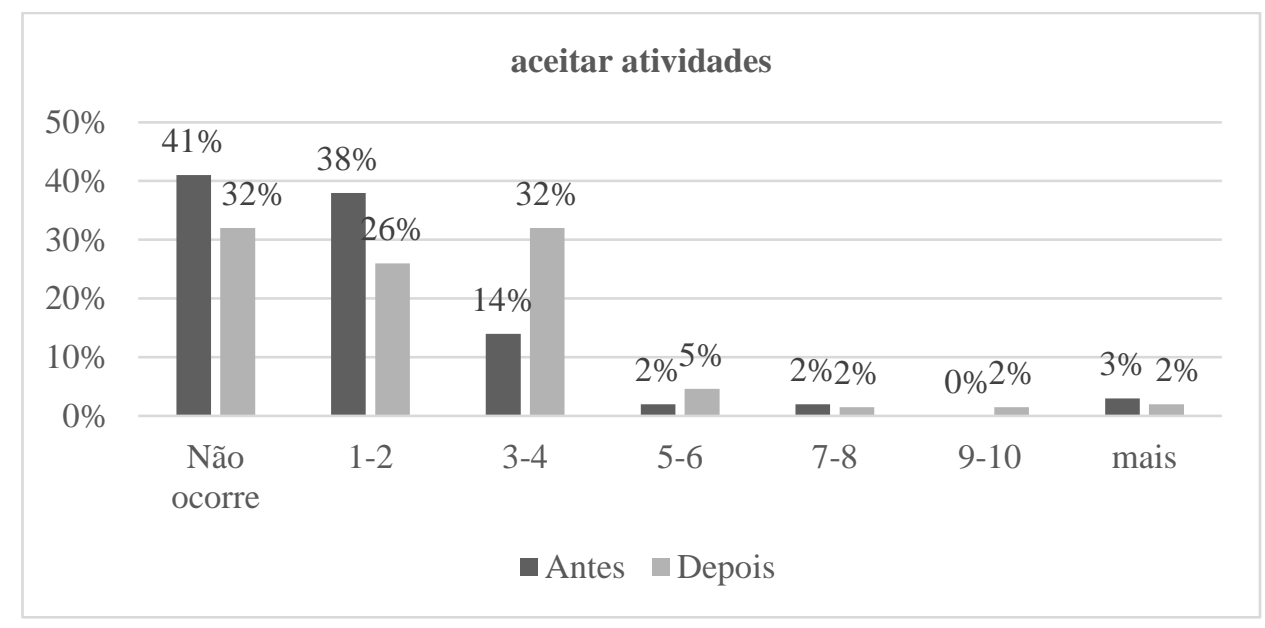

Fonte: Autores (2021).

Em média, houve um aumento de $9 \%$ nas ocorrências de dificuldades em aceitar as atividades escolares. Na pesquisa qualitativa de Sousa et al. (2020) verificou-se que apesar dos materiais e atividades escolares ajustadas e adaptadas conforme a singularidade e especificidade do aluno, houve pouco interesse em realizar as propostas, indo de encontro a pesquisa em questão, na qual observou-se aumento na dificuldade dos alunos com TEA em aceitar as atividades fora do ambiente escolar, este pouco interesse com as tarefas escolares, é resultante da oscilação de humor, mudança de rotina e manutenção do distanciamento social, estes fatores que surgiram como desafios, concomitante a falta de terapias, o que ocasionou a regressão no comportamento e acentuação das características do Transtorno.

O Gráfico 3 foi construído a partir das respostas acerca da categoria de Lazer, que objetivou identificar quais atividades eram realizadas durante o distanciamento social. Os cuidadores responderam a pergunta "Quais atividades de lazer atuais da criança ou adolescente?', 
Gráfico 3. Atividades de lazer praticadas pelas crianças e adolescentes.

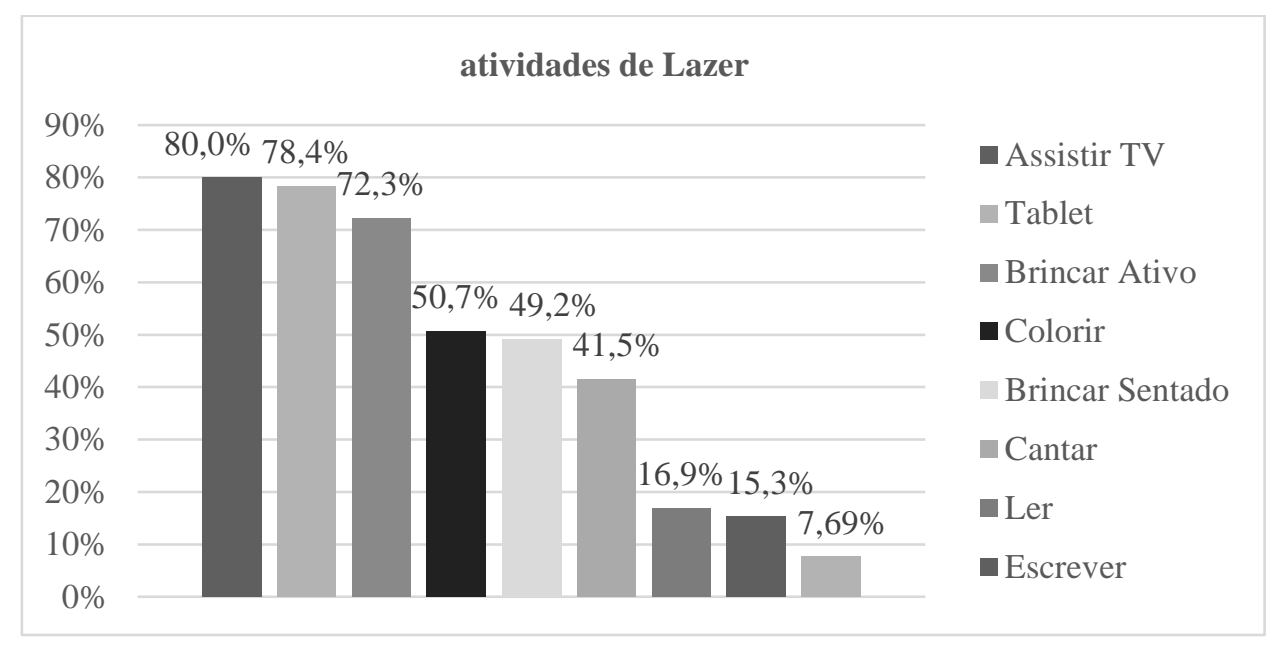

Fonte: Autores (2021).

Com base nos dados acerca das modificações ocorridas, é possível notar no gráfico acima que, no contexto do lazer, houve um grande impacto na rotina das crianças, à medida que houveram repercussões negativas nos aspectos comportamentais, já que 44,61\% (n=29) das crianças e adolescentes reclamaram das interrupções geradas pela COVID-19.

Nos relatos trazidos pelos responsáveis durante o preenchimento do formulário, apontaram que a criança apresentava constante desejo de sair de casa e quando era explicado sobre a quarentena a criança manifestava comportamentos agressivos, em outro relato uma mãe trouxe que seu filho sentia a falta de passear no parque e de ir à igreja aos domingos.

A partir dos resultados quanto ao lazer praticado por essas crianças e adolescentes; a tv $80 \%(\mathrm{n}=52)$ e tablet $78,4 \%$ $(n=51)$ se mostraram atraentes nessa condição de distanciamento social. No entanto, Brito (2018) ressalta o quão pode ser prejudicial o excesso mediante a longas horas em frente aos meios eletrônicos, as mídias digitais como (televisão, videogames, jogos eletrônicos, tablets e internet) tornaram-se, nos últimos anos, um elemento cultural significativo na rotina de crianças.

O Gráfico abaixo permite observar a frequência de participação dos responsáveis durante as atividades de lazer das crianças e adolescentes. Buscou-se identificar se houveram diferenças nesta frequência antes e durante o distanciamento social.

Gráfico 4. Participação dos responsáveis nas atividades de lazer.

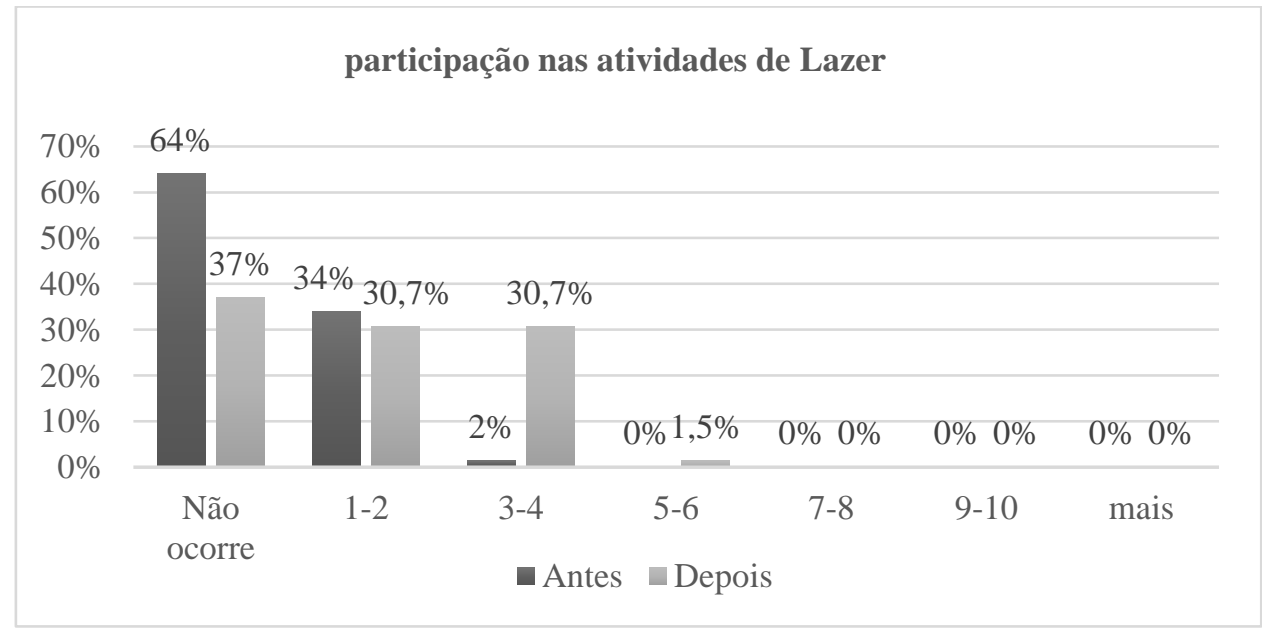

Fonte: Autores (2021). 
Identificou-se que a participação dos responsáveis antes da pandemia era baixa, pois 64\% (n=41) dos responsáveis afirmaram que não participavam das atividades de lazer antes do distanciamento social. Após o seu início, a maioria dos responsáveis afirmaram que passaram a participar mais das atividades de lazer, esse aumento representou em média de $27 \%$ na participação. Segundo Bellomo et al. (2020) as famílias tiveram que se reorganizar para acomodar e modificar as mudanças na rotina dessas crianças e adolescentes, em razão de alguns hábitos que não puderam ser mantidos.

A reflexão sobre a urgente necessidade de um distanciamento social em que pais e filhos precisam ficar mais tempo dentro de casa, os responsáveis tiveram que manter os compromissos de trabalho e obrigações diárias fazendo com que esses apresentassem mais responsabilidades, o que culmina em cansaço, exaustão e dificulta na organização de um momento de lazer, de brincadeira, de qualidade e com significado para ambos (Santos \& Cardoso, 2021).

Vários fatores podem influenciar no brincar de uma criança, entre eles estão ambiente restrito, baixo estímulo, socialização com outras crianças e aspectos relacionados a condição de saúde. Com isso, os responsáveis necessitam criar e organizar para essas crianças ou adolescente ambientes que possam favorecer um brincar adequado (Albuquerque \& Benitez, 2020).

Segundo Cotonhoto e Rosseti (2016) a brincadeira é fundamental para a criança, pois é o modo pelo qual a mesma se apropria do mundo que a cerca. Ao brincar, a criança passa a compreender sua cultura, valores, hábitos, desejos, relações com o outro e vivencia experiências de seu contexto circundante.

Quanto aos dados relacionados ao brincar sentado, colorir, cantar, ler, ressalva-se que as atividades de lazer podem ser ações livres ou que surgem em determinado momento do dia, mas que, devem ser conduzidas pela criança, já que proporciona, diminuição do estresse, maior aprendizado, desenvolvimento de habilidades, favorece o vínculo parental, linguagem, além de proporcionar uma maior capacidade de imaginação para essas crianças ou adolescentes (Santos \& Cardoso, 2021).

O que se pode observar com esta pesquisa é que anteriormente a pandemia da COVID-19, não ocorria uma participação grande desses responsáveis no que se refere ao lazer das crianças e adolescentes com TEA. Porém, com o novo contexto, houve uma mudança tanto no comportamento quanto no aumento de horas em que essas atividades eram desempenhadas, assim, os responsáveis buscaram minimizar os impactos e buscaram ser mais ativos às necessidades em que essas crianças e adolescentes apresentavam.

No estudo de Faro et al. (2020) em que objetivou comparar dois grupos de mães de crianças com TEA (mães com e sem estresse), o qual aborda a sobrecarga de cuidado, autonomia da criança e a sua percepção de suporte familiar, foi observado que o estresse houve maior predominância entre os sintomas psicológicos.

Os dados destacam que tanto no Brasil quanto em outros países há um impacto direto na qualidade de vidas desses responsáveis na qual verifica que os cuidadores apresentam dificuldades em conciliar e dar prosseguimento em suas atividades profissionais em conjunto com a quantidade de exigência com relação aos cuidados que uma pessoa com TEA pode apresentar (Cusinato et al., 2020).

Quanto a categoria "Terapias", o primeiro ponto questionado, tratou-se de quais terapias a criança ou adolescente realizava em um contexto pré-pandemia. Nessa categoria os responsáveis poderiam selecionar e adicionar quantas terapias desejassem.

Foram citados 15 tipos de terapias: Terapia de Fala (fonoaudiologia) 76,92\% (n=50), Terapia Ocupacional Convencional 50,76\% ( $\mathrm{n}=33)$, Psicoterapia 49,23\% ( $\mathrm{n}=32)$, Terapia de Integração Sensorial 36,92\% ( $\mathrm{n}=24)$, Terapia ABA 33,84\% ( $\mathrm{n}=22)$, Psicomotricidade 21,53\% (n=14), Equoterapia, Fisioterapia e Psicopedagogia com 7,69\% ( $\mathrm{n}=5)$, Teacch 6,15\% $(n=4)$, Musicoterapia 4,61\% (n=3), Denver, Esportes Adaptados, Hidroterapia e Educação Física 1,53\% (n=1) cada um.

A alta intensidade nos atendimentos terapêuticos a pessoas com TEA é indicada em diversos estudos, a exemplo da Terapia de Análise Aplicada do Comportamento (ABA) que, segundo Ferreira, Silva, Melo e Barros (2016), preconizam a alta 
frequência de sua aplicação (30 a 40 horas semanais), minimamente 2 anos de duração e a precocidade do início das intervenções.

Zwaigenbaum et al., (2015) em sua pesquisa sobre a intervenção precoce apontou que o tratamento tardio nas crianças com TEA piora gravemente os resultados nos aspectos comportamentais, cognitivos e de linguagem.

Indivíduos com TEA apresentam dificuldades na comunicação e interação social, dessa forma os ambientes em que estavam inseridas como: escola, terapias, parque eram sensíveis a recebê-las e a desafiavam no desenvolvimento das habilidades com déficits. O isolamento ou distanciamento social por si só já restringem o contato com outras pessoas que poderiam possibilitar novas formas de comunicação diferentes de seus pais (Bellomo et al. 2020).

Acerca das abordagens utilizadas no tratamento de crianças com TEA, o estudo "Prática Baseada em Evidências para Crianças, Adolescentes e Jovens Adultos com Autismo" (Steinbrenner et al. 2020), apontou que a Terapia ABA, Terapia de Integração Sensorial estão entre as Terapias baseadas em evidências cientificamente comprovadas e eficazes no tratamento de pessoas com o transtorno, o que converge com o estudo, pois essas apareceram em 33,84\% ( $n=22)$ e $36,92 \%$ ( $n=33$ ) das respostas dos responsáveis, respectivamente.

Embora os resultados dessa pesquisa evidenciarem que grande parte das crianças e adolescentes recebem tratamentos de fonoaudiologia e psicoterapia não foram encontrados estudos que abordavam sobre as adaptações ou dificuldades de manter esses atendimentos durante a pandemia da covid-19.

Também, foi perguntado aos participantes se "Houve interrupções das Terapias? Se sim, quantas foram interrompidas?". $100 \%$ dos responsáveis afirmaram que houveram interrupções nas terapias. Sendo que 84,61\% $(n=55)$ dos responsáveis relataram que todas as terapias foram interrompidas, 7,69\% $(n=5)$ disseram que apenas uma terapia foi interrompida, 4,61\% $(n=3)$ disseram que apenas duas terapias haviam sido suspensas e 3,07\% (n=2) não souberam responder.

Outro questionamento foi se as crianças e adolescentes sentiam falta dessas assistências que antes eram prestadas de forma presencial. Os resultados mostraram que 56,92\% $(n=37)$ dos participantes com TEA sentiram sim a falta, por outro lado $33,84 \%$ ( $n=22$ ) não mostraram sentir falta e 9,23\% ( $n=6$ ) não souberam responder.

Questionou-se também se alguma terapia foi adaptada, se houve teleconsulta ou alguma outra forma de atendimento alternativo. $61,53 \%(\mathrm{n}=40)$ dos responsáveis responderam que as terapias não foram adaptadas para o contexto domiciliar e $38,46 \%(\mathrm{n}=25)$ foram adaptadas. A maioria das adaptações foram teleconsultas ou telemonitoramento, programas estruturados, entre outras formas.

Segundo os responsáveis as Terapias que foram adaptadas são: Terapia Ocupacional Convencional, Terapia de Fala (fonoaudiologia), Terapia ABA, Terapia de Integração Sensorial, Psicoterapia, Psicopedagogia e Psicomotricidade, o que corresponde a apenas $46,66 \%$ das 15 terapias descritas pelos participantes.

$\mathrm{O}$ afastamento das terapias e tentativa de inserção nos teleatendimentos pode trazer diversos prejuízos, visto que os graus de acometimento do Transtorno variam e podem tornar a adaptação ao atendimento virtual dificultosa, em função das características do TEA, principalmente quando se fala de casos severos. O mesmo vale para as aulas via internet para esse público.

No relato de caso de Nadler, Godwin \& Dempsey (2020) é apresentada uma criança diagnosticada com TEA durante as interrupções ocorridas com a pandemia, diversos desafios foram descritos, como a perda de emprego e estado de saúde frágil dos pais, moradia localizada na área rural e ainda a falta de centros especializados próximo a sua residência, o que dificultou ainda mais no momento relatado, visto que o deslocamento a longa distâncias estava sendo evitado, ou mesmo proibido, seu atendimento médico foi suspenso, assim como as terapias, o que acarretou em desordens sensoriais e comportamentais, com alta ocorrência de comportamentos autolesivos que o levaram a necessitar de um pronto-socorro e ainda houve aumento na dosagem de seus medicamentos.

Esse relato traz a realidade de diversas famílias que têm uma pessoa com TEA em sua composição, os prejuízos aos 
quais esses passaram vão além das questões comportamentais, atravessam as dificuldades econômicas até as socioemocionais graves.

Os dados constatam nítidas repercussões negativas ocasionadas pela COVID-19 no cotidiano, em específico, das crianças e adolescentes com TEA durante o distanciamento social. Uma necessidade que impactou rotinas e relacionamentos, uma vez que foram afetados os comportamentos, a alimentação, o contexto escolar, o lazer e as terapias.

Notou-se que os comportamentos listados (heterolesivos, autolesivos, birras, ecolalia e flapping) sofreram uma alteração significativa do "antes" para o "depois" analisado no decorrer da pesquisa, assim como nas terapias, as quais tiveram de ser interrompidas de forma abrupta. Dessa maneira, observa-se o quanto a pandemia e a quarentena foram fatores prejudiciais, junto com a consequência da descontinuidade no tratamento especializado, que desencadearam ou intensificaram os comportamentos disruptivos na maioria das crianças e adolescentes com TEA.

Embora os resultados dessa pesquisa evidenciarem que grande parte das crianças e adolescentes recebem tratamentos de fonoaudiologia e psicoterapia não foram encontrados estudos que abordavam sobre as adaptações ou dificuldades de manter esses atendimentos durante a pandemia da covid-19.

\section{Considerações Finais}

Por fim, podem ser elencadas algumas limitações no estudo, como três respostas que foram dadas por profissionais que não acompanhavam as crianças e os adolescentes com TEA em grande parte do seu dia (professora, equoterapeuta e mediadora), isso pode ter reduzido a fidelidade das respostas fornecidas no questionário. Além disso, houve dificuldades em relação ao levantamento de materiais bibliográficos que pudessem dar maior base ou discutir certas questões que foram levantadas durante o estudo, o qual pode acontecer em decorrência da atualidade do tema. Dessa forma, sugere-se o desenvolvimento de novas pesquisas acerca do tema, a fim de contribuir para as práticas com essas famílias, crianças e adolescentes com o TEA, bem como aporte cientificos para os profissionais que atuam com o público supracitado e ainda discussões das temáticas e problemáticas levantadas nesse estudo.

\section{Referências}

Albuquerque, I., \& Benitez, P. (2020). O brincar e a criança com transtorno do espectro autista: revisão de estudos brasileiros. Revista Ibero-Americana de Estudos em Educação, 15(4), 1939-1953. https://doi.org/10.21723/riaee.v15i4.12811

American Psychiatric Association. (2014). DSM-5: Manual diagnóstico e estatístico de transtornos mentais. Artmed Editora.

Araripe, N. B., Brito, A., De Sá, D. C., Ruguê, G. F. S., Machado, H. B., Bauer, J. A. T., Gonçalves Neto, J. U., Da Cruz, K. R. S., \& Lacerda, L. (2019). Novos arranjos em tempos de covid-19: apoio remoto para atendimento de crianças com transtorno do espectro autista. Revista Brasileira de Análise do Comportamento, 15(2). https://doi.org/10.18542/rebac.v15i2.8768

Barbosa, A. M., Figueiredo, A. V. d., Viegas, M. A. S., \& Batista, R. L. N. F. F. (2020). Os impactos da pandemia covid-19 na vida das pessoas com transtorno do espectro autista. Revista da Seção Judiciária do Rio de Janeiro, 24(48), 91. https://doi.org/10.30749/2177-8337.v24n48p91-105

Barros, I. B. d. R., \& Fonte, R. F. L. d. (2016). Estereotipias motoras e linguagem: aspectos multimodais da negação no autismo. Revista Brasileira de Linguística Aplicada, 16(4), 745-763. https://doi.org/10.1590/1984-639820169895

Bellomo, T. R., Prasad, S., Munzer, T., \& Laventhal, N. (2020). The impact of the COVID-19 pandemic on children with autism spectrum disorders. Journal of Pediatric Rehabilitation Medicine, 13(3), 349-354. https://doi.org/10.3233/prm-200740

Borba, M. M. C., \& Barros, R. S. (2018). Ele é autista: como posso ajudar na intervenção? Um guia para profissionais e pais com crianças sob intervenção analítico-comportamental ao autismo. Cartilha da Associação Brasileira de Psicologia e Medicina Comportamental.

Brasil. (2020) Sobre a doença: O que é COVID-19. Ministério da Saúde. Recuperado em Abril 8, 2020, em https://www.gov.br/saude/pt-br/coronavirus/o-quee-o-coronavirus.

Brito, A. R., Almeida, R. S., Crenzel, G., Alves, A. S. M., Lima, R. C., Abranches, C. D. (2020) Autismo e os novos desafios impostos pela pandemia da COVID19. Revista de Pediatria SOPERJ, 1-6.

Brito, R. (2018). Estilos de mediação do uso de tecnologias digitais por crianças até aos 6 anos. CIED da investigação as práticas. 8(2). doi:10.25757/invep.v8i2.155. 
Colizzi, M., Sironi, E., Antonini, F., Ciceri, M. L., Bovo, C., \& Zoccante, L. (2020). Psychosocial and Behavioral Impact of COVID-19 in Autism Spectrum Disorder: An Online Parent Survey. Brain Sciences, 10(6), 341. https://doi.org/10.3390/brainsci10060341

Cavaleiro Corrêa, V. A., Nascimento, C. A. V. d., \& Omura, K. M. (2020). Isolamento social e ocupações. Revista Interinstitucional Brasileira de Terapia Ocupacional - REVISBRATO, 4(3), 295-303. https://doi.org/10.47222/2526-3544.rbto34486

Cotonhoto, L. A., \& Rossetti, C. B. (2016). Prática de jogos eletrônicos por crianças pequenas: o que dizem as pesquisas recentes?. Revista Psicopedagogia, 33(102), 346-357.

Cusinato, M., Iannattone, S., Spoto, A., Poli, M., Moretti, C., Gatta, M., \& Miscioscia, M. (2020). Stress, Resilience, and Well-Being in Italian Children and Their Parents during the COVID-19 Pandemic. International Journal of Environmental Research and Public Health, 17(22), 82-97. https://doi.org/10.3390/ijerph17228297

Da Silva, V. R. F., Silveira, R. M. C. F., \& Prsybyciem M. M. (2020). A inclusão de alunos com Transtorno do Espectro Autista (TEA) e orientação psicológica em tempos pandêmicos: suas relações e desafios na educação. Revista Práxis, 12(1), 77-85.

Dartora, D D., Mendieta, M C., \& FranchinI, B. (2014). A equipe de enfermagem e as crianças autistas. Journal of Nursing and Health, (1), 27-38. doi: 10.15210/JONAH.V4I1.4304

Faro, K. C. A., Santos, R. B., Bosa, C. A., Wagner, A., \& Silva, S. S. d. C. (2019). Autismo e mães com e sem estresse: análise da sobrecarga materna e do suporte familiar. Psicologia, 50(2). https://doi.org/10.15448/1980-8623.2019.2.30080

Ferreira, L. A., Silva, A., Melo, J., \& Barros, R S. (2016). Ensino de aplicação de tentativas discretas a cuidadores de crianças diagnosticadas com autismo. Perspectivas em Análise do Comportamento, (7): 101-113. doi: 1018761/pac.2015.034

Gerhardt, T. E., Silveira, D. T (2009). Métodos de Pesquisa. Universidade Aberta do Brasil - UAB/UFRGS. Editora da UFRGS

Kalvin, C. B., Jordan, R. P., Rowley, S. N., Weis, A., Wood, K. S., Wood, J. J., Ibrahim, K., \& Sukhodolsky, D. G. (2021). Conducting CBT for Anxiety in Children with Autism Spectrum Disorder During COVID-19 Pandemic. Journal of Autism and Developmental Disorders. https://doi.org/10.1007/s10803-02004845-1

Lázaro, CP, \& Pondé, MP (2017). Narrativas de mães de crianças com transtornos do espectro do autismo: enfoque no comportamento alimentar. Tendências em psiquiatria e psicoterapia, 39, 4-11.

Macêdo, F. D. O. A., Lopes, K. A. P., Lopes, L. A. M. R., \& de França Cruz, R. (2020). Ações e experiências de terapeutas ocupacionais no contexto de pandemia da COVID-19/Occupational Therapists actions and expiriences in the COVID-19 pandemic context. Revista Interinstitucional Brasileira de Terapia Ocupacional - REVISBRATO, 4(3), 318-333.

Monteiro, M. A., Santos, A. A. A. D., Gomes, L. M. M., \& Rito, R. V. V. F. (2020). Transtorno do espectro autista: uma revisão sistemática sobre intervenções nutricionais. Revista Paulista de Pediatria, 38.

Nadler, C., Godwin, DL, Dempsey, J., \& Nyp, SS (2021). Autismo e acesso aos cuidados durante a crise do COVID-19. Journal of Developmental \& Behavioral Pediatrics, 42 (1), 73-75.

Narzisi, A. (2020). Handle the autism spectrum condition during Coronavirus (COVID-19) stay at home period: Ten tips for helping parents and caregivers of young children. Brain Sciencies. 10 (4), 207. https://doi.org/10.3390/brainsci10040207.

O. P. A. S. (2020). Folha informativa-COVID-19: doença causada pelo novo coronavírus. 22 de maio 2020. <https://www.paho.org/bra/index.php?option=com_content\&view=article\&id=6101: covid19\&Itemid=875>.

Rodgers, RF, Lombardo, C., Cerolini, S., Franko, DL, Omori, M., Fuller-Tyszkiewicz, M., ... \& Guillaume, S. (2020). O impacto da pandemia COVID-19 no risco e sintomas de transtorno alimentar. International Journal of Eating Disorders, 53 (7), 1166-1170.

Santos, M. W., \& Cardoso, M. C. (2021). Educação e infância: Pandemia, tecnologias e o distanciamento das crianças: Education and childhood: Pandemic, technologies and children's distance. Revista Cocar, (9).

Silva, M. R., da Silva, P. C., Rabelo, H. D., \& de Vasconcellos Vinhas, B. C. (2020). A Terapia Ocupacional pediátrica brasileira diante da pandemia da COVID19: reformulando a prática profissional/Brazilian pediatric Occupational Therapy before the COVID-19 pandemic: reformulating professional practice. Revista Interinstitucional Brasileira de Terapia Ocupacional - REVISBRATO, 4(3), 422-437.

Silva, T. R., Mariotti, M. C., \& Bridi, A. (2020). Aprendendo a lidar com as mudanças de rotina devido ao Covid-19: Orientações Práticas para Rotinas Saudáveis/Learning to deal with change routine due to COVID-19: guidelines healthy routine practices. Revista Interinstitucional Brasileira de Terapia Ocupacional - REVISBRATO, 4(3), 519-528.

Soares, A. P. T., da Silva, B. M., Santos, L. S., \& Gama, G. L. (2020). Transtorno do Espectro Autista (TEA): Conhecimento e Sobrecarga dos Pais. Saúde e Desenvolvimento Humano, 8(3), 09-16.

Sousa, D. D. L. D. S. (2020). Desafios explicitados por famílias de estudantes com transtorno do espectro do autismo (TEA) durante a pandemia de covid-19. Anais VII CONEDU-Edição Online... Campina Grande: Realize Editora.

Souza, V R B. A atuação do terapeuta ocupacional com base na Teoria da Integração Sensorial na assistência de crianças com Transtorno do Espectro Autista (TEA) durante a pandemia do Covid-19. Revista Interinstitucional Brasileira de Terapia Ocupacional - REVISBRATO. 2020; (4): 371-379. doi: 10.47222/25263544.rbto34026 
Research, Society and Development, v. 10, n. 16, e115101623242, 2021

(CC BY 4.0) | ISSN 2525-3409 | DOI: http://dx.doi.org/10.33448/rsd-v10i16.23242

Steinbrenner, J. R., Hume, K., Odom, S. L., Morin, K. L., Nowell, S. W., Tomaszewski, B., ... \& Savage, M. N. (2020). Evidence-Based Practices for Children, Youth, and Young Adults with Autism. FPG Child Development Institute.

Sterponi, L., \& de Kirby, K. (2016). Uma reavaliação multidimensional da linguagem no autismo: Insights de um estudo analítico do discurso. Journal of autism and developmental disorder, 46 (2), 394-405.

Tudela Torras, M., \& Abad Más, L. (2019). Reducción de las conductas autolesivas y autoestimulatorias disfuncionales en los trastornos del espectro del autismo a través de la terapia ocupacional. Medicina (Buenos Aires), 79, 38-43.

Zobel-Lachiusa, J., Andrianopoulos, M. V., Mailloux, Z., \& Cermak, S. A. (2015). Sensory differences and mealtime behavior in children with autism. American Journal of Occupational Therapy, 69(5), 1-8.

Zwaigenbaum, L. Bauman, M L. Choueiri, R. Kasari, C. Carter, A. Granpeesheh, D. (2015). Intervenção precoce para crianças com tran storno do espectro do autismo com menos de 3 anos de idade: recomendações para prática e pesquisa. Pediatria. 5(136), 60-81. 